\title{
Energy Saving Potential Due to Refurbishment of Federal Public Housing in the UAE
}

\author{
Wafa AlAwadhi ${ }^{1}$, Athari AlNaqbi ${ }^{1}$, Abeer Manneh ${ }^{1}$, Ayoub Kazim ${ }^{2}$, Bassam Abu-Hijleh ${ }^{1}$ \\ ${ }^{1}$ Faculty of Engineering \& IT, The British University in Dubai, Dubai-UAE \\ ${ }^{2}$ Dubai International Academic City, Education Cluster, TECOM Investments, Dubai-UAE \\ Email: bassam.abuhijleh@buid.ac.ae
}

Received 2013

\begin{abstract}
This paper, computer energy modeling is used to estimate the potential energy savings of refurbishing existing public federal housing in the United Arab Emirates. Such houses are built by the UAE Ministry of Public Works (MoPW) in five of the seven emirates that make up the UAE federation. The energy modeling was performed using the Integrated Environmental Solutions-Virtual Environment (IES-VE) commercial software. The study covered representative MoPW houses built in the period of 1974-2012. The results indicate potential energy savings upto $30.8 \%$ for the case of model 717 when refurbished to 2 Pearls standards compared to the as built configuration. The results showed little benefit in going from 1 Pearl to 2 Pearls refurbishment level. Thus 1 Pearl seems to be the most practical. This shows the high potential for energy, and thus environmental, savings should refurbishment be carried out on the homes built by the MoPW.
\end{abstract}

Keywords: energy modeling, energy savings, refurbishment, UAE

\section{Introduction}

Sustainability features prominently in the UAE's 2021 vision. This includes increased determination in the UAE to reduce $\mathrm{CO} 2$ emissions as part of the global effort to reduce greenhouse gases and mitigate global warming effects. Although the focus has been on developing and expanding the use of renewable energy resources, reducing energy consumption per capita is also an important aspect. The built environment has been identified as one of the highest energy consumption sectors in the UAE, and thus $\mathrm{CO}_{2}$ producers. The focus until now has been on regulations for new buildings. As a young country, UAE compulsory building regulations relating to energy savings and conservation were introduced only in the past decade (2003 in Dubai and 2007 in Abu Dhabi). This means that even if all new buildings are to adhere to significantly high energy conservation standards, the UAE will still have a large stock of buildings, some just completed, which have excessive cooling loads and thus are not environmentally friendly. This can be seen from the data that shows the UAE to have one of the highest electricity consumption per capita in the world. This reflects negatively on the $\mathrm{CO} 2$ emissions as the UAE has the 2nd highest $\mathrm{CO} 2$ emissions per capita in the world. If the UAE is to significantly reduce its $\mathrm{CO} 2$ footprint the inefficiencies of the existing building stock needs to be addressed.

This paper presents the result of a computer energy modeling study designed to assess the potential energy savings of refurbishing existing buildings in the UAE. In particular, public housing buildings built by the UAE Ministry of Public Works (MoPW). The MoPW has been building such public housing since 1974 and until today. The existence of detailed data regarding the number and the construction details of such buildings made them idea for this study. The study will look at the energy consumption of a representative building in each decade and see the level of energy reduction that can be achieved using different refurbishment practices, e.g. extra insulation and changing the glazing.

\section{Literature Review}

The built environment is responsible for approximately $40 \%$ of the total primary energy consumption [1]. Although most of the new regulations focus on new buildings to be constructed, these new buildings add around $0.5-2 \%$ to the total building stock, depending on the type and the regional economic conditions [2 and 3]. This means that even if all new buildings have zero $\mathrm{CO} 2$ 
emissions, the older inefficient building stock will cause the CO2 emission levels to remain unacceptably high. Thus refurbishment of existing buildings seems to be the most practical way of reducing $\mathrm{CO} 2$ emissions in the short to medium term [4]. The maturity of refurbishment technologies, practices and relatively low costs, makes refurbishment a better choice for reducing CO2 emissions compared to using more active, and expensive, renewable energy strategies to meet the high demand of inefficient buildings. Many studies have been conducted, in different countries, to assess the potential and needs for refurbishment of existing buildings [3, 5-8]. The scope of these studies covered the environmental, social and economic aspects of the refurbishment process. In all cases, the results clearly showed the benefits of refurbishing older buildings. The scope of the refurbishment process is strongly dependent on the age of the building, building technologies employed in the original build, building materials used as well as the local climatic conditions and environmental regulations.

As a young country, the UAE has been late in implementing energy conservation regulations for buildings. These regulations started with the 2003 Decree 66 in which Dubai Municipality started enforcing the use of energy saving practices, i.e. thermal insulation materials and glazing. Similar regulations were also decreed in Sharjah in the same year, i.e. 2003. It was not until 2010 that building regulations were decreed in Abu Dhabi. That is when the Abu Dhabi Urban Planning Council (UPC) produced the ESTIDAMA building regulations which included several energy saving requirements. Form this it is clear that the majority of the buildings in the UAE were constructed with little or no consideration to energy savings. This is especially true for investment buildings built by developers for sale rather than rent. In such situations initial cost savings were the dominate concern for the developers resulting in cost/corner cutting measures. As a result such buildings tended to suffer from high energy operating costs. It is interesting to note that until 2012 there are no federal building regulations designed to promote energy savings in federal buildings. This includes all the federally build public houses starting from 1974 until today. The harsh climate of the UAE coupled with poor thermal characteristics of buildings in the UAE resulted in very high cooling loads. The highest electrical load comes from HVAC equipment which accounts for an average of $40 \%$ of the total year around electrical load and up to $60 \%$ of the peak electrical load during the summer time [9]. Based on this the current study will focus on the energy saving potential of refurbishing exiting buildings in the UAE due to refurbishment of the building envelop in order to improve its thermal characteristics.
Several federal public housing villas will be studied in this research to assess the energy saving potential due to refurbishment. These federal buildings were chosen due to the availability of detailed data describing the buildings construction characteristics as well as numbers and years of built. Five different villa models were chosen for this study. The models were chosen were the most popular model built by the MoPW in each of the past 5 decades, i.e. from 1974 until 2012. . Table 1 shows a summary of the main data for these villas. The new ESTIDAMA thermal insulation and glazing requirements are used to guide the level of refurbishment applied for the different villas. ESTIDAM has five certification levels ranging from 1-5 Pearls [10]. Two refurbishment levels will be used in the current study, those corresponding to 1 and 2 Pearls. Table 2 lists the minimum ESTIDAMA thermal requirements for 1 and 2 Pearls certification.

Table 1. Summary data of the five villa modles used in the current study.

\begin{tabular}{|c|c|c|c|c|}
\hline $\begin{array}{c}\text { Model } \\
\text { number }\end{array}$ & $\begin{array}{c}\text { Decade } \\
\text { built }\end{array}$ & $\begin{array}{c}\text { Villa } \\
\text { Configuration }\end{array}$ & $\begin{array}{c}\text { Total floor } \\
\text { area }\left(\mathrm{m}^{2}\right)\end{array}$ & $\begin{array}{c}\text { Window/wall } \\
\text { ratio (\%) }\end{array}$ \\
\hline C73 & $1970 s$ & G & 108 & \\
\hline B74 & $1980 s$ & G & 114 & 3.7 \\
\hline 670 & $1990 s$ & G & 351 & 6.7 \\
\hline 717 & $2000 s$ & G+1 & 394 & 11.5 \\
\hline 762 & $2010 s$ & G+1 & 472 & 11.1 \\
\hline
\end{tabular}

Table 2. Minimum ESTIDAMA thermal requirements for 1 and 2 Pearls certification.

\begin{tabular}{|l|c|c|}
\cline { 2 - 3 } \multicolumn{1}{c|}{} & 1 Pearl & 2 Pearls \\
\hline Wall U-value (W/m C $\left.{ }^{\circ}\right)$ & 0.32 & 0.29 \\
\hline Roof U-value (W/m C $\left.{ }^{\circ}\right)$ & 0.14 & 0.12 \\
\hline Glazing U-value (W/m $\left.{ }^{2} \mathrm{C}^{\circ}\right)$ & 2.2 & 1.9 \\
\hline $\begin{array}{l}\text { Glazing Solar Heat Gain Coefficient } \\
\text { (SHGC) }\end{array}$ & 0.4 & 0.3 \\
\hline $\begin{array}{l}\text { Maximum Window/Wall area ratio } \\
(\%)\end{array}$ & $15 \%$ & $10 \%$ \\
\hline
\end{tabular}

\section{Methodology}

Computer modeling has proven to be a powerful tool among building professionals and researchers, whether they are used for drawing, rendering, evaluating or optimization. A Computer simulation modeling program simulates an abstract model of a particular building and can be used to explore and gain new design ideas, technological products and verdicts. Computer energy modeling is a subset of this category and is used to enhance buildings' designs and systems through assessing and estimating the performance of a building and its integrated systems. 
Such programs and models are used when systems are too complex for an analytical assessment. This type of modeling assists designers in processing building regulations, simulate solar analysis, thermal analysis, acoustic analysis, ventilation and air flow, create shading designs and lighting designs within a 3D model. There is a wide range of energy simulation software available that have been used by researchers including; Energy plus [11], DOE-2 [12 and 13], Ecotect [14 and 15], and IES [16 and 17]. For this work, the Integrated Environmental Solutions - Virtual Reality (IES-VE) software was chosen due to high level of accuracy and range of capabilities.

Five different MoPW built villas were selected for this study The MoPW built several models in each decade since 1974 and until today. The villas chosen were the most popular models built in each decade.

Each villa was modeled in IES based on the design data provided by the MoPW. This included architectural, structural and material components. Figure 1 shows a sample the IES villa model (model 717). IES was used to calculate the energy consumption of the different villas. This was done for the original configuration of the villas, i.e. as built, as well after the virtual refurbishment of the villas by adding additional insulation or upgrading the existing glazing. The effectiveness of the refurbishment was assessed by looking at the percentage change in the energy consumption of the refurbishment villa compared to the energy consumption of the original villa. These results will be shown and discussed in the following section.

After taking a closer look at the layout and plans of the different models, it became clear that models C73 and B74 are essentially the same in terms of configuration and build technology. Thus model C73 was not simulated.

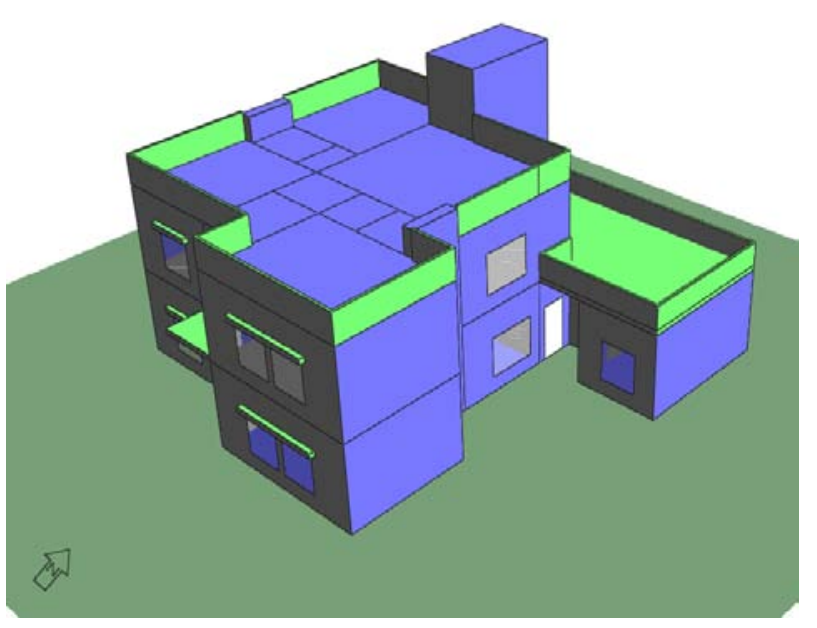

Figure 1. The IES computer model of villa model 717.

\section{Results and Discussion}

IES energy modeling computer modeling software was used to simulate the total energy load of each of the four villa models over an entire year. Each model was simulated as per built configuration them after refurbishing it to ESTIDAMA's 1 and 2 Pearl standards. Note that the 2 Pearls standard requires a window/wall ration of less than $10 \%$. Still not change in the models w/w was made as per of the virtual refurbishment exercise as this was deemed unpractical in real-life refurbishment. Also from Table. 1 shows that only models 717 and 762 had a w/w ratio greater than $10 \%$ but not by much.

Table. 3 show the total annual energy load (TAEL) for the four villa models and how this changes with refurbishment levels. It is interesting that all four models exhibit similar trends and even values in terms of energy reduction due to refurbishment. The refurbishment to 1 Pearl level resulted in a significant 27.5-29.8\% reduction in total energy. Going to 2 Pearls level did not improve the energy performance much over the 1 Pearl level, only an addition $0.7-1.1 \%$. This is clear indication that 1 Pearl insulation levels are good enough for the UAE climate and further enhancements in these values have little in terms of return.

Table 3. Changes in the total energy consumption due to upgrading the models' thermal chatacteristics.

\begin{tabular}{|c|c|c|c|}
\hline Model number & $\begin{array}{c}\text { Total Annual } \\
\text { Energy Load } \\
(\mathrm{MWh})\end{array}$ & $\begin{array}{c}\text { Change in TAEL } \\
\text { compared to } \\
\text { based model (\%) }\end{array}$ & $\begin{array}{c}\text { Normalized } \\
\text { TAEL } \\
(\mathrm{kWh} / \mathrm{m} 2)\end{array}$ \\
\hline B74 (base) & 54.7 & NA & 480 \\
\hline B74 (1 Pearl) & 39 & $28.7 \%$ & 342 \\
\hline B74 (2 Pearls) & 38.6 & $29.4 \%$ & 339 \\
\hline 670 (Base) & 188.5 & NA & 537 \\
\hline 670 (1 Pearl) & 134.7 & $28.5 \%$ & 384 \\
\hline 670 (2 Pearls) & 132.7 & $29.6 \%$ & 378 \\
\hline 717 (Base) & 237.2 & NA & 602 \\
\hline 717 (1 Pearl) & 166.4 & $29.8 \%$ & 422 \\
\hline 717 (2 Pearls) & 164.1 & $30.8 \%$ & 416 \\
\hline 762 (Base) & 174.9 & NA & 371 \\
\hline 762 (1 Pearl) & 126.8 & $27.5 \%$ & 269 \\
\hline 762 (2 Pearls) & 125 & $28.5 \%$ & 265 \\
\hline
\end{tabular}

Table. 3 also show the normalized total annual energy load per $\mathrm{m}^{2}$ of the models gross floor area. This is an indicator of the energy efficiency of the different models (TAEL). It is interesting to note that between the 1980s (B74) and the 2000s (717), the energy consumption per $\mathrm{m}^{2}$ has gone up. The increase in window/wall ratio during that period (Table. 1) coupled with poor thermal 
glazing characteristics, all models had single pan glass windows, resulted in high solar heat gain loads and thus the increase in the normalized TAEL. Model 762 has the lowest normalized TAEL although it has a high $11.1 \%$ w/w glazing but the glazing used has much better thermal characteristics than the other models, U-glazing for model 762 is $2.83 \mathrm{~W} / \mathrm{m}^{2} \mathrm{~K}$ compared to $4.83 \mathrm{~W} / \mathrm{m}^{2} \mathrm{~K}$ from model 717 . Note that the value of the U-glazing for model 762 is close to that required by the 1 Pearl regulations, Table. 1.

Figure. 2 gives a better idea as to the impact of upgrading the thermal envelop of the different models. Figure. 2 shows the monthly total energy load for the three configurations of villa model 670 . The biggest reduction occurs during the hot summer months. This is when the effect of the extra thermal insulation is strongest. It is interesting to note that the extra insulation actually resulted in a slight increase in the energy consumption during the relatively cool months of December and January. The energy modeling done did not account for using natural ventilation when the outside temperature is low. Thus the extra insulation trapped the heat inside the villa and did not allow for proper heat rejection to the surroundings during the colder nights of December and January. Similar trends were also noted for the other three models in this study.

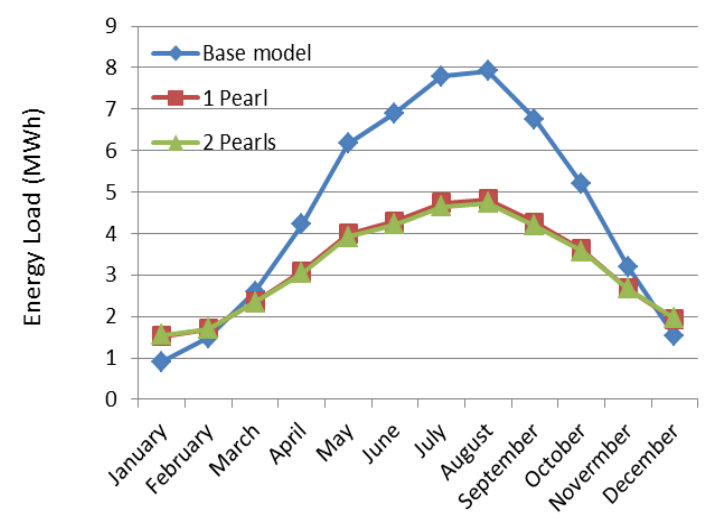

Figure. 2 The monthly total energy consumption for the villa model 670.

\section{Conclusions}

Computer energy modeling was used to assess the energy savings that could result from enhancing the thermal insulation characteristics of public housing in the UAE. Four models representing public housing built during the past five decades were chosen for this study. Two levels of virtual refurbishment were done for each of the four models. The results showed annual energy savings ranging from $27.5 \%-30.8 \%$. here was little extra energy con- sumption reduction when going from 1 Pearl to 2 Pearls thermal requirements. Thus upgrading to 1 Pearl requirements seems to be the most practical and economical course of action.

\section{Acknowledgement}

This work was supported by the Emirates Foundation, ExxonMobil and GASCO under Grant 2011/157.

\section{REFERENCES}

[1] C. Petersdorff, T. Boermans, O. Stobbe, S. Joosen, W. Graus, E. Mikkers and J. Harnisch, Mitigation of $\mathrm{CO} 2$ Emissions from the Building Stock, Beyond the EU Directive on the Energy Performance of Buildings, ECOFYS, Cologne Germany, 2010.

[2] A. Peacock, P.F. Banfill, S. Turan, D. Jenkins, M. Ahadzi, G. Bowles, D. Kane, M. Newborough, P.C. Eames, H. Singh, T. Jackson and A. Berry, "Reducing CO2 emissions through refurbishment of non-domestic UK buildings," presented at the Improving Energy Efficiency in Commercial Buildings (IEECB) Conference, Frankfurt -Germany, 10 - 11 April 2008.

[3] C. Langston, F. Wong, E. Hui and L. Shen, "Strategic assessment of building adaptive reuse opportunities in Hong Kong,” Building and Environment, Vol. 43, 2008, pp 1709-1718.

[4] M. Sunikka and C. Boon, 'Environmental Policies and efforts in social housing: the Netherlands," Building Research \& Information, Vol. 31, 2003, pp 1-12.

[5] A. Papadopoulos, T. Theodosiou and K. Karatzas, "Feasibility of energy saving renovation measures in urban buildings The impact of energy prices and the acceptable payback time criterion,” Energy and Buildings, Vol. 34, 2002, pp 455-466.

[6] A. Mickaityte, E. Zavadskas, A. Kaklauskas and L. Tupenaite, "The concept model of sustainable buildings refurbishment,” Int. J. of Strategic Property Management, Vol. 12, 2008, pp 53-68.

[7] S. Hong, J. Gilbertson, T. Oreszczyn, G. Green and I. Ridley, "A field study of thermal comfort in low-income dwellings in England before and after energy efficient refurbishment,” Building and Environment, Vol. 44, 2009, pp 1228-1236.

[8] J. Ouyang, J. Ge. And K. Hokao, 'Economic analysis of energy-saving renovation measures for urban existing residential buildings in China based on thermal simulation and site investigation,” Energy Policy, Vol. 37, 2009, pp 140-149.

[9] Dubai Electric and Water Authority site: http://www.dewa.gov.ae/community/conservation/ydc/sav epower.aspx (accessed February 15, 2010).S. Chen, B. Mulgrew, and P. M. Grant, "A clustering technique for digital communications channel equalization using radial basis function networks," IEEE Trans. on Neural Networks, Vol. 4, 1990, pp. 570-578.

[10] Estidama-Pearl rating tem. http://www.estidama.org/pearl-rating-system-v10.asp 
x?lang=en-US, accessed October 2012.

[11] N. Fumo, P. Mago \& R. Luck. Methodology to estimate building energy consumption using EnergyPlus Benchmark Models. Energy and Buildings, Vol. 42, 2010, pp. 2331-2337.

[12] S. Cho \& S. Haberl. Integrating Solar Thermal and Photovoltaic Systems in Whole Building Energy Simulation. Fourth National Conference of IBPSA-USA, New York City, New York, August 11 - 13, 2010, pp. 344-351

[13] J. Lam, K. Wan, D. Liu \& C. Tsang. 2010. Multiple regression models for energy use in air-conditioned office buildings in different climates. Energy Conversion and Management, Vol. 51, 2010, pp. 2692-2697.

[14] D. Raia, B. Sodagarb, R. Fieldsonc \& X. Hud 2011. Assessment of CO2 emissions reduction in a distribution warehouse Energy, Vol. 36, 2011, pp. 2271-2277.
[15] Y. Saadah \& B. AbuHijleh. 2010. Decreasing CO2 Emissions and Embodied Energy during the Construc-tion Phase Using Sustainable Building Materials. International Journal of Sustainable Building Technology and Urban Development, Vol. 1, 2010, pp. 115-120.

[16] S. Azhar, W. Carlton, D. Olsen \& I. Ahmad. Building information modeling for sustainable design and LEED ${ }^{\circledR}$ rating analysis. Energy and Buildings, Vol. 42, 2010, pp. 1888-1895

[17] N. Al-Masri and B. Abu-Hijleh, ”Courtyard Housing in Midrise Buildings - An Environmental Assessment in Hot-Arid Climate," Renewable \& Sustainable Energy Reviews, Vol. 16, 2012, pp. 1892-1898. 